\title{
Investigation of the deformations character of the Rudny fault shores during the development of the Yuzhnoye Deposit, Primorsky Krai
}

\author{
Iuliia Fedotova*1 \\ Mining Institute FEB RAS, 51 Turgenev st., Khabarovsk, 680000, Russia
}

\begin{abstract}
In seismically active areas, ore-controlling faults play an important role in the geodynamics of underground mining of rockbursthazardous vein deposits. Moreover, the nature of deformations of the shores of such faults depends on a combination of various factors. The article presents the results of research conducted on the basis of visual observations of the author in the workings and the analysis of the database of measurements of distances between pairs of reference points of the observation station No. 1, installed on the "Rudny" fault of the "Yuznoye" section of the "2 Sovetsky" mine for the period 2012-2019. The analysis made it possible to identify the nature of deformations, establish their cyclical nature and rhythms of changing types of vibrations.
\end{abstract}

\section{Introduction}

The geodynamic situation in the Far East is caused by the zone of active interaction between the Amur and Okhotsk lithospheric plates, which is still occurring at the present time. According to the data of the Federal research center of the unified geophysical service of the Russian Academy of Sciences (FRC UGS RAS), only within a radius of five hundred kilometers within the Dalnegorsk ore belt, 232 earthquakes with magnitudes from 3.4 to 7 were registered in the period from 2000 to 2018 [1].

Development of vein hydrothermal deposits by underground method in such conditions directly depends on the geomechanical state of the geological environment, which is manifested not only in the formation of a mosaic structure of stress fields [2, 3], and, accordingly, deformations of various blocks, but also in the implementation of rock pressure and mining-induced earthquakes. Moreover, the situation worsens with depth, especially in high rockburst-hazardous deposits. Seismically active faults that intersect the developed fields when the geodynamic situation changes can lead to the destruction of underground workings in a dynamic form within one or more horizons to significant movements along the boundaries of structural blocks and, as a result, the implementation of mining-induced earthquakes.

A wide range of geophysical, geomechanical, and geodesic methods and measurement tools are currently used to assess changes in the state of the rock mass of rockbursthazardous deposits under development. This article discusses the results of using geodesic

${ }^{1}$ Corresponding author: fjulia@mail.ru 
methods, in particular, measuring the distances between pairs of reference points of an observation station located in the vicinity of an active ore-controlling fault. Direct geodetic measurements in the array can reveal the nature of its deformation and the degree of influence of various natural and man-made factors on these changes [2, 3].

\section{The object of research}

The Yuzhnoye polymetallic deposit is currently operated by the Yuzhny section of the "2 Sovetsky” mine of JSC MMC Dalpolymetal. The deposit is located $22 \mathrm{~km}$ from the village Krasnorechensk, Dalnegorsk district, Primorsky krai of the Russian Federation. It is located $42 \mathrm{~km}$ from the city of Dalnegorsk, where there is a central processing plant that processes the deposit's ores. The ore is delivered to the factory by road.

The Yuzhnoye deposit is located on the western slope of the Sikhote-Alin ridge, in the interfluve of the upper reaches of the Bolshaya Ussurka and Rudnaya rivers. The area of the deposit is characterized by a strongly dissected mid-mountain terrain with relative excess of watersheds over the key valleys of $250-400 \mathrm{~m}$.

The deposit is a hydrothermal high-medium temperature vein type. Its formation was inextricably linked with the tectonic and magmatic history of the entire ore region. Discontinuous faults in the field are developed very widely. According to orientation in space, they are divided into north-eastern and north-western ones. Faults of the northeastern stretch are the earliest. These are the main ore-containing structures for ore bodies. Faults of the north-west strike are widely manifested in the field. They are expressed by zones of intense fracturing and brecciation with a capacity of one to ten meters, consisting of systems of closely parallel cracks with friction clay, consistent with the general stretch of the zones. Often these disturbances are controlled by dikes of quartz diorites, diorite and diabase porphyrites.

The post-ore discontinuous tectonics in the deposit is very weak. Only in isolated cases, there are shifts of ore bodies along faults of the north-west direction. The maximum number of geodynamic phenomena within the developed deposit occurred at 500-600 m.

The Rudny fault is ore-controlling and can be traced on all horizons. The apparent thickness of the fault crossing the workings is from $0.1 \mathrm{~m}$ to $0.5 \mathrm{~m}$. The main performance is carbonated. The fracturing of the massif in the vicinity of the fault is parallel, secant, and often filled with calcite. The fracture interval of the host rocks is from 2 to $5 \mathrm{~m}$.

Since the beginning of operation of the deposit Yuzhnoye at relatively shallow depths (170 $\mathrm{m}$ from the surface), there have been strong rockbursts, including severe consequences. And in 1986, at depths below the horizon of $760 \mathrm{~m}$ (170 $\mathrm{m}$ from the surface), it was classified as dangerous for rockbursts.

Previously performed assessments of the stress state of the deposit array using complex geomechanical methods allowed us to establish that the stress field in the deposit area is heterogeneous and characterized by a shear type, which is dominated by subhorizontal compressive stresses oriented in the north-east direction and exceeding the gravitational component by 1.8 times [4-6]. The obtained results of stress measurements in the deposit array are in good agreement with GPS observations, which record the general movement of tectonic blocks in the upper part of the earth's crust at an average speed of 3.5-4.0 cm/year in a south-easterly direction [7].

Significant spatial heterogeneity of physical and mechanical properties of ores and rocks is due to the genesis of the formation of the geological environment of the deposit [8]. The potential impact hazard of certain types of rocks of the deposit is confirmed by the implementation of destruction in the workings in a dynamic form in the form of shooting, formation of separate blocks of rocks and shocks. 
Due to the very complex structural framework of the deposit, it is necessary to conduct more detailed zoning of the deposit sections as the array is opened and prepared, as well as blocks are worked out. At the same time, it is necessary to observe the most active faults [9].

Research, the results of which are reviewed in this article were based on visual observations in the mine workings and the author made the analysis of the database measurements of distances between pairs of reference points of observing stations No. 1 (Fig.1) for the period of 2012-2019 years, provided to the author section of forecast and warning of rockbursts of the "Yuzhnoye" section of the mine "2 Sovietsky."

Reference points of the observation station No. 1 are installed along the shores of the "Rudny" fault that crosses the workings (level $+480 \mathrm{~m}$, Field gallery).

Measurements of the movement of pairs of reference points 1-3 and 2-4 on the left and right sides are carried out by the surveyor service of the site using a tape measure with a frequency of 1 time per week. In the diagram (Fig.1), the arrows show the direction of measurements between pairs of reference points.

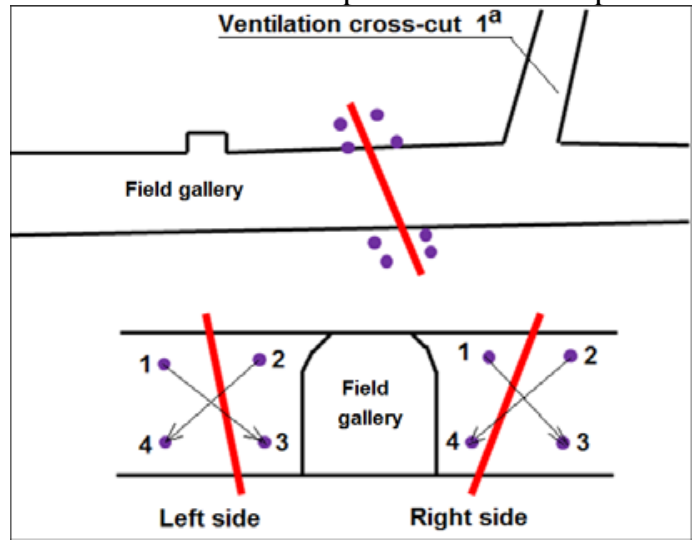

a)

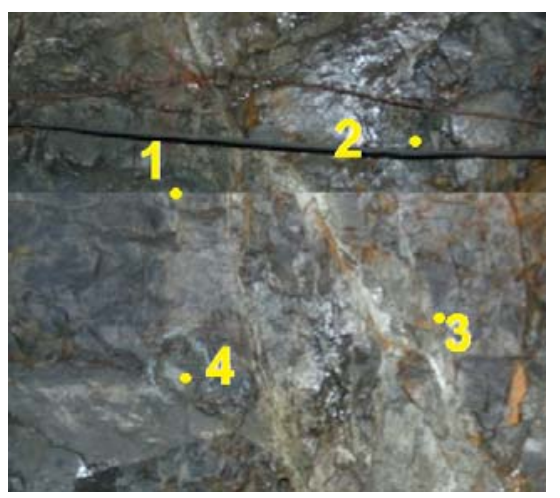

b)

Fig. 1. Diagram of the observation station No. 1 of rock block movements relative to the Rudny fault at $+480 \mathrm{~m}$ (a) and the view of the station on the left side of the workings (b). In figure (a): red line the fault; purple points - the reference points of observations

\section{Research results}

To determine the nature of the fault shores movement relative to each other, the analysis of the changes magnitude in the distances between pairs of reference points located in the same direction relative to the axis of the fault was performed: 1-3 left and 2-4 right (Fig.2a); 2-4 left and 1-3 right (Fig.2b).

The data shown in Fig. 2 shows that until the end of November 2013, the fault banks experienced almost no deformations, with the exception of July 2013, when changes in the distances between the reference points were registered by $5 \mathrm{~mm}$. Until October 2013, block development and sinking had no significant impact on the fault. As the work front approaches the fault, there is a gradual increase in the values of changes in the distances between the reference points until the end of February 2015. Then, the fault shores began to actively move relative to each other with an intensity of up to $15-30 \mathrm{~mm}$ within a week. The maximum distance changes relative to previous measurements were recorded in January-February 2016, August 2016, and April 2017, March and May 2018, and FebruaryMarch 2019. At the same time, before the first maximum of changes (01-02.2016), the fault activation was observed for 9 months; the second (08.2016) - 1 month; the third (04.2017) 
- 3 months; the fourth - the longest (03.2018) - 11 months; the fifth (05.2018) - 3 months; the sixth (02-03. 2019) - 4 months.
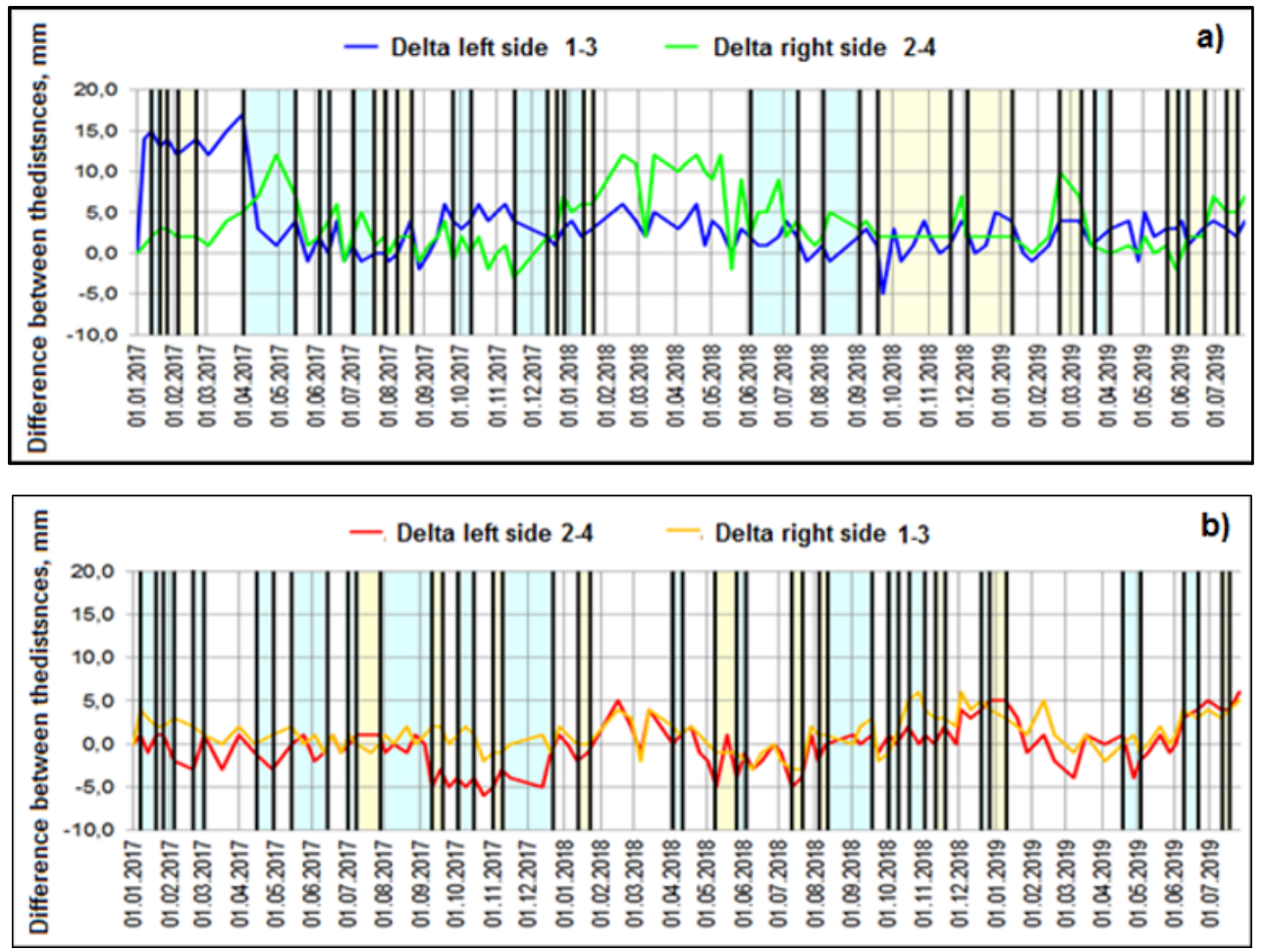

Fig. 2. Changes in the values of distances between pairs of reference points: a) 1-3 on the left side and 2-4 on the right, b) 2-4 on the left side and 1-3 on the right, located on the shores of the Rudny fault at level $+480 \mathrm{~m}$. The color indicates the periods of changing types of fluctuations in the values of distance changes: white - in-phase; blue - antiphase; yellow - no changes in the values in one pair

When comparing data, Fig.2A and 2B, it is seen that there are several characteristic features: 1 - the amplitude of the vibrations at pairs of 1-3 left side and 2-4 right three times more than 2-4 pairs of left side and right 1-3; 2 - envelopes of the sine wave oscillatory motions in pairs of 2-4 starboard behind half period from the pair 1-3 on the left side until the end of 2018; 3 - fluctuations 2-4 pairs of left side and right 1-3 - mostly in phase, with the exception of the period 01.09.2017 for 01.04.2018, when the background of a pronounced sinusoid pairs 2-4 left side there is almost a flat line for the pair 1-3 right.

Comparison of diagrams of changing types of fluctuations in the values of distances between the reference points 1-3 on the left side and 2-4 on the right (Fig. 3A) and 2-4 on the left side and 1-3 on the right (Fig.3b), located along the shores of the Rudny fault, revealed the following trends.

For pairs of reference points 1-3 on the left side and 2-4 on the right (Fig. 3a), the following sequence of the number of peaks of changing types of vibrations is characteristic: 2-2-2-1-2-2-3-1-2-1. In this case, changes in the types of vibrations are observed in the following combinations: $1-3-1 \rightarrow 1-3-1 \rightarrow 1-2-1 \rightarrow 1-2-1 \rightarrow 1-3-1 \rightarrow 1-3-1 \rightarrow 1-2-1 \rightarrow 1-$ 3-1 $\rightarrow$ 1-3-1 $\rightarrow$ 1-2-1 $\rightarrow$ 1-2-1 $\rightarrow$ 1-3-1 $\rightarrow$ 1-3-1 $\rightarrow$ 1-3-1 $\rightarrow$ 1-2-1 $\rightarrow$ 1-3-2 $\rightarrow$ 2-3-1 $\rightarrow$ 3-1. 

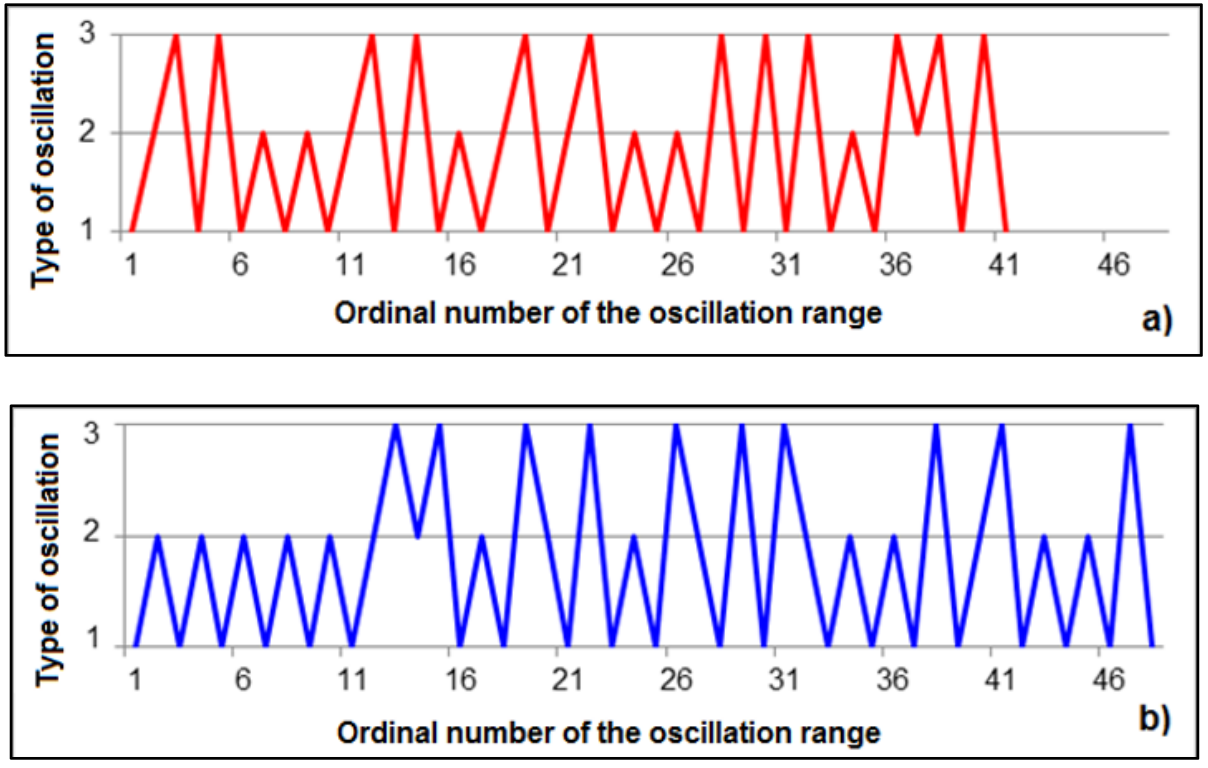

Fig. 3. Diagram of changing types of vibrations when changing the distance between pairs of reference points located on the shores of the "Rudny" fault on the level $+480 \mathrm{~m}$ : a) 1-3 left and 2-4 right; b) 2-4 left and 1-3 right. Oscillation type: 1 - in-phase; 2 - anti-phase; 3 - no changes in values in one pair

It can be seen that only at the end of the analyzed period (from 20.05.19 to 20.06.19) there was a change in the types of fluctuations in the combination 1-3-2 $\rightarrow$ 2-3-1, and mainly it occurred in the combinations 1-3-1 (56\%) and 1-2-1 (33\%).

At the same time, for pairs of reference points 2-4 on the left side and 1-3 on the right (Fig.3b), there is a different sequence of the number of peaks of changing types of vibrations: 5-2-1-2-1-3-2-2-2-1. In this case, the change occurred in the following combinations of changes in the types of vibrations:

$$
1-2-1 \rightarrow 1-2-1 \rightarrow 1-2-1 \rightarrow 1-2-1 \rightarrow 1-2-1 \rightarrow 1-3-2 \rightarrow \text { 2-3-1 } \rightarrow \text { 1-2-1 } \rightarrow \text { 1-3-1 } \rightarrow \text { 1-3-1 }
$$

$\rightarrow$ 1-2-1 $\rightarrow$ 1-3-1 $\rightarrow$ 1-3-1 $\rightarrow$ 1-3-1 $\rightarrow$ 1-2-1 $\rightarrow$ 1-2-1 $\rightarrow$ 1-3-1 $\rightarrow$ 1-3-1 $\rightarrow$ 1-2-1 $\rightarrow$ 1-2-1

$\rightarrow 1-3-1$.

In contrast to the pairs of reference points 1-3 on the left side and 2-4 on the right, the change of oscillation types in the combination 1-3-2 $\rightarrow$ 2-3-1was observed in the period from 10.07.17 to 20.10.17, while the rest of the time it occurred in the combinations 1-3-1 (38\%) and 1-2-1 (52\%). In this case, the initial period of observations (up to 10.07.17) is characterized by a change of types only in the combination 1-2-1.

Fig. 4 shows the results of comparing the registered manifestations during the study period with changes in the movements of each of the reference pairs relative to the initial series of measurements. 


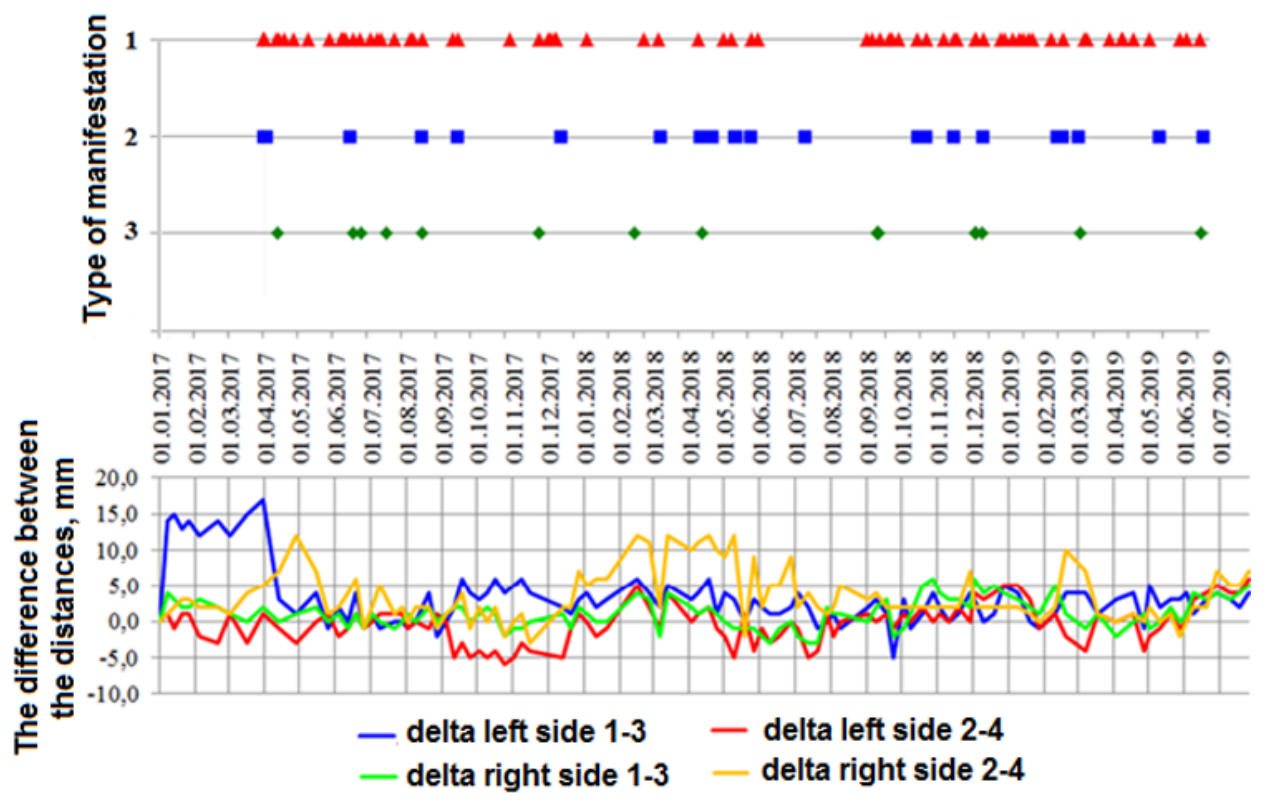

Fig. 4. The nature of changes in deformations along the "Rudny" fault and manifestations provoked by rock pressure

As shown in figure 4, there is no clear correspondence between the time of registration of rock pressure manifestations and changes in the behavior of the fault. Most likely, this is due to the fact that a database of manifestations registered within the mine field is being compared.

\section{Conclusion}

The analysis of the database of measurement results of distances between pairs of reference points of observation station No. 1 on the Rudny fault for the period 2012-2019 revealed the following patterns.

1. A common feature of changes in the values of distances for the analyzed pairs is that over the entire period of observations, three characteristic types of their fluctuations are distinguished: 1) in-phase (changes in values for different pairs occur with the same sign); 2) antiphase (changes in values occur with the opposite sign) and 3) when changes in the value of one pair do not change the value of the second.

2. The analysis made it possible to reveal a certain tendency to cyclical changes - about once every six months, fluctuations in the values of the change in the distance between pairs of reference points on different sides of the fault increase sharply. However, the magnitude of these changes over time is uneven.

3 . For the analyzed reference pairs, the change of oscillation types in the combination 13-2 $\rightarrow$ 2-3-1 was observed once during the entire observation period, and the rest of the time the change of types occurred in the combinations 1-3-1 and 1-2-1. Moreover, the combination 1-3-1 is more common in pairs of frames 2-4 of the left and right side 1-3, and the combination of 1-2-1 - off frames 1-3 of the left side and 2-4 on the right.

The revealed specificity of rock block fluctuations along the two shores of the Rudny fault can probably be explained as follows.

On the one hand, we can assume that, perhaps, the reference point No. 3 is located in the body of the fault, and not on its shore. This assumption can be confirmed or disproved 
by installing additional reference points (in the fault body and on its shores), as well as by measuring the distances between them, but also by leveling the profile that crosses the fault.

On the other hand, this specificity may be related to the trigger effect of uneven intensity of the impact of ongoing mining operations on different sides of the fault.

Since the "Rudny" fault is only controlling for individual structural blocks of the rock mass, it is necessary to conduct more detailed studies of this issue at an expanded observation station.

\section{Acknowledgements}

The author expresses deep gratitude to the chief miner of JSC "MMC "dalpolymetall" Osadchey S. P., the head of SPPRB Krasnozhenov N. G. and the chief geologist Shishkina V. I. (section "Yuzhnoye"of the mine "2 Sovetsky") for assistance in conducting visual observations on the horizons of the mine and providing data for analysis.

\section{References}

1. Electronic resource http://www.ceme.gsras.ru/new/ssd.htm

2. A. A. Panzhin, A. D. Sashurin, Ferrous metallurgy, 1, 21-25 (2017)

3. A. D. Sashurin, A. E. Balek, A. A. Panzhin, C. V. Usanov, Gorny Zhurnal, 12, 16-20 (2017)

4. Yu. Yu. Pelenkov, Physico-technical problems of mining, 2, 11-22 (1995)

5. K. G. Levi, S. I. Sherman, V. A. Sankov and others. Map of modern geodynamics of Asia. Scale 1: 5000000 (Irkutsk: IZK SB RAS, 2007)

6. I. Yu. Rasskazov, Pacific Geology, 5(25), 104-114 (2006)

7. V. Yu. Timofeev, D. G. Ardyukov, P. Yu. Gornov, E. V. Boyko, A.V. Timofeev, Problems of seismicity and modern geodynamics of the Far East and Eastern Siberia, 6165 (Khabarovsk, 2010)

8. I. Yu. Rasskazov, G. A. Kursakin, M. I. Potapchuk, etc., Physico-technical problems of mining, 5, 125-134 (2012)

9. E. V. Kasparyan, Iu. V. Fedotova, N. N. Kuznetsov, Proceedings of the Fersman scientific session of the MI KSC RAS Apatity, 14, 282-285 (2017) 